\title{
Tipps und Tricks: Kontermutter
}

\author{
$\square$ Dankward Höntzsch
}

Manchmal ist es eine große Herausforderung, bei sehr kleinen distalen Femurkondylenfragmenten und/oder bei periprothetischen Frakturen bei Knietotalendoprothese dieses kleine Kondylenfragment mit Plattenosteosynthese, vornehmlich winkelstabilen Platten, zu halten.

Ein wirksamer Trick ist, dass eine Kontermutter auf der Gegenseite verwendet wird. Hierzu gibt es seit Langem Muttern, welche auf konventionelle Kortikalisschrauben aufgeschraubt werden können. Das heißt, die Kortikalisschraube wird von der Platte durch die Kondyle,
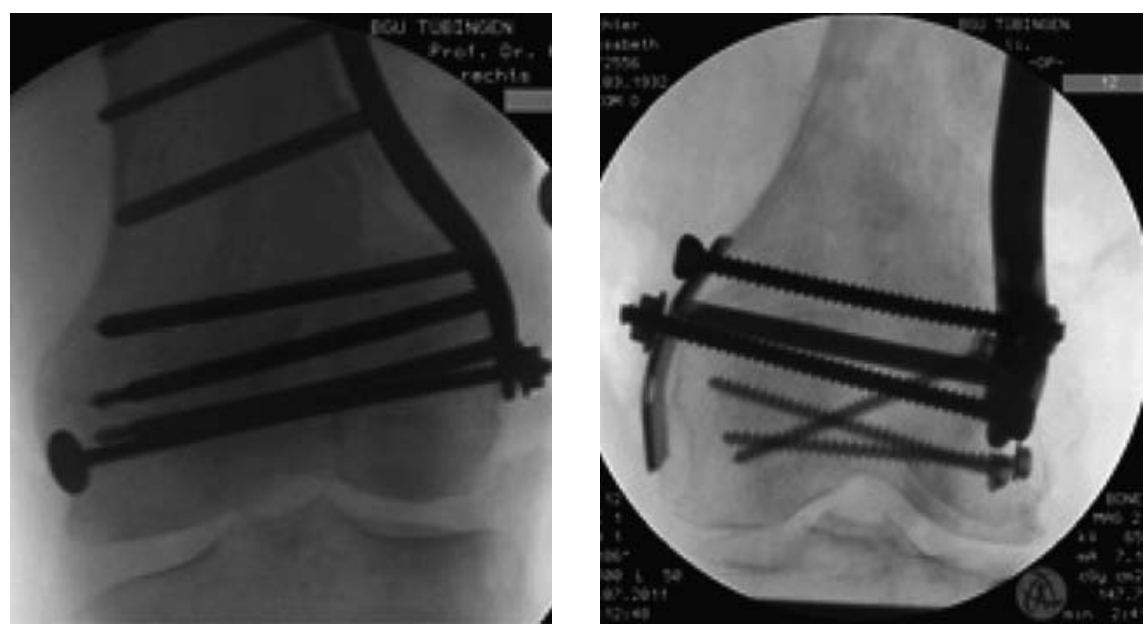

ggf. an der Knieprothese vorbei, durch die mediale Kortikalis gebohrt und auf der Gegenseite mit einer Kontermutter besetzt.

Es ist auch die gegenläufige Version möglich. Einfacher ist aber, von der Platte her zu arbeiten. Dann kann nämlich einfach mit dem Vorbohrer vorgebohrt werden und die Gegeninzision wird wie beim Durchdringen eines SteinmannNagels dort gesetzt, wo der Bohrer und/ oder die Schraube herauskommt. Es wird dann eine sehr lange, am besten die längste (mehr als $100 \mathrm{~mm}$ ) Kortikalisschraube verwendet. Auf das weit über- stehende Ende wird die Mutter als Kontermutter aufgesetzt (Abb.) und gegen die Kortikalis befestigt. Die Haltekraft ist so groß, dass diese Mutter auch in den Knochen hereingezogen werden kann. Wenn man eine größere „Unterlegscheibe“ haben will, kann eine 2- oder 3Loch-Drittelrohrplatte oder 3,5-mmPlatte als Konter verwendet werden.

Bei periprothetischen Frakturen können diese Schrauben auch schräg gesetzt werden, sodass sie „einfach“ an den Knieprothesen, je nach Bedarf, vorbeigeschraubt werden können.
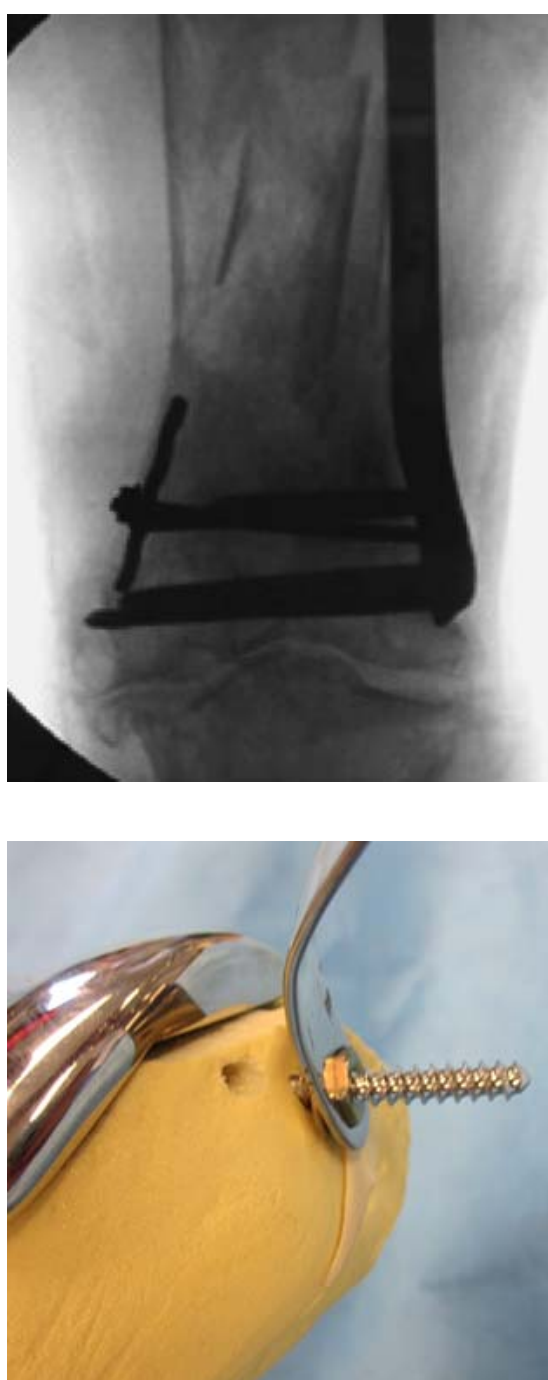

OP-JOURNAL 2016; 32: 160

(c) Georg Thieme Verlag KG Stuttgart · New York DOI http://dx.doi.org/10.1055/s-0042-117125 